\title{
Molecular and proteomic insight into Notch1 characterization in hepatocellular carcinoma
}

\author{
Catia Giovannini ${ }^{1,2}$, Manuela Minguzzi ${ }^{1,2}$, Filippo Genovese ${ }^{1,3}$, Michele Baglioni $^{1}$, \\ Alessandra Gualandi, ${ }^{1,3}$, Matteo Ravaioli ${ }^{4}$, Maddalena Milazzo ${ }^{1}$, Simona Tavolari ${ }^{1,5}$, \\ Luigi Bolondi ${ }^{1,2}$, Laura Gramantieri ${ }^{1}$ \\ ${ }^{1}$ Center for Applied Biomedical Research (CRBA), S.Orsola-Malpighi University Hospital, Bologna, Italy \\ ${ }^{2}$ Department of Medical and Surgical Sciences, University of Bologna, Bologna, Italy \\ ${ }^{3}$ C.I.G.S., University of Modena and Reggio Emilia, Bologna, Italy \\ ${ }^{4}$ Department of Medical and Surgical Sciences, General and Transplant Surgery Unit, University of Bologna, Bologna, Italy \\ ${ }^{5}$ Department of Experimental Diagnostic Specialty Medicine, University of Bologna, Bologna, Italy \\ Correspondence to: Catia Giovannini, email: catia.giovannini4@unibo.it
}

Keywords: Notch1, invasion, proteomic, markers, HCC

Received: July 24, 2015

Accepted: April 10, 2016

Published: May 06, 2016

\section{ABSTRACT}

Hepatocellular carcinoma (HCC) ranks fifth in frequency worldwide amongst all human cancers causing one million deaths annually. Despite many promising treatment options, long-term prognosis remains dismal for the majority of patients who develop recurrence or present with advanced disease. Notch signaling is an evolutionarily conserved pathway crucial for the development and homeostasis of many organs including liver. Herein we showed that aberrant Notch 1 is linked to HCC development, tumor recurrence and invasion, which might be mediated, at least in part, through the Notch1-E-Cadherin pathway. Collectively, these findings suggest that targeting Notch1 has important therapeutic value in hepatocellular carcinoma. In this regard, comparative analysis of the secretome of HepG2 and HepG2 Notch1 depleted cells identified novel secreted proteins related to Notch 1 expression. Soluble E-Cadherin (sE-Cad) and Thrombospondin-1 (Thbs1) were further validated in human serum as potential biomarkers to predict response to Notch1 inhibitors for a tailored individualized therapy.

\section{INTRODUCTION}

Hepatocellular carcinoma (HCC) is the third leading cause of cancer mortality worldwide with an increased incidence throughout the world [1]. Although the introduction of screening programs among high-risk populations leads to earlier diagnosis, the majority of patients present with intermediate or advanced-stage disease. Sorafenib (Nexavar) remains the only systemic therapy recognized to improve overall survival in patients with advanced HCC [2]. However, for patients who are intolerant of or progress on sorafenib no other drug has been approved as second line option [3]. Thus, the development of new agents to block HCC progression is the primary research objective. Notch pathway has been described to be involved in cell fate determination, cell differentiation, proliferation and death
[4]. Notch promotes cell survival, angiogenesis and treatment resistance in numerous cancers, making it a promising target for cancer therapy $[5,6]$. It also crosstalks with other critical oncogenes, providing a means to affect numerous signaling pathways with one intervention [5]. Most of the studies have focused on Notch1 which has been shown to be associated to invasion and metastasis in pancreatic cancer cells [7], in prostate cancer [8] and in melanoma [9]. Data regarding Notch1 involvement in HCC are limited and ambiguous in terms of anti-tumoral effects following its inhibition $[10,11]$, a discrepancy that may be due to the high context dependency of the Notch cascade [12]. We and Zhou reported abnormal accumulation of Notch1 in HCC compared to surrounding non tumor tissue $[13,14]$ raising the possibility that deregulation of Notch1 receptor may participate to HCC tumorigenesis and cancer progression. 
Set of Notch inhibitors have been developed. Most of these inhibitors show anti-tumor effects in preclinical studies [15]. Anti-Notch2 treatment blocks the development of a broad range of tumors in a mouse model with primary liver cancer whereas the inhibition of Notch1 increases the development of cholangiocarcinoma like tumors [16]. However, environmental factors are also involved in routes to HCC development suggesting that Notch pathway activation should be analysed in different liver cancer models as previously discussed [16].

Blocking monoclonal antibodies (mAb) directed against Notch1 are under investigation [17]. However, serum biomarkers to predict response to Notch inhibitors are not available. Similarly, it is not always possible to obtain tumor tissue samples to test Notch1 expression in patients with HCC on cirrhosis who may display coagulation impairments or other contraindications. Therefore, the use of serum markers related to the expression of Notch1 could be of great help in clinical practice.

To this aim, we have performed a quantitative proteomic analysis of the culture media of HepG2 cells against Notch1 depleted cells using a gel free approach. We have identified secreted proteins involved in cytoskeleton organization, cell adhesion and regulation of cellular metabolic process that can be considered as sensitive indicators of Notch1 expression. Since among the secreted proteins were identified proteins involved in cell adhesion, we analysed whether Notch1 could play a role in the invasion of liver cancer cells. Interestingly, we found out that Notch1 regulates the EMT (Epithelialmesenchymal-transition) process for which E-Cadherin is a well-established hallmark. We also found out that Notch1 regulates E-Cadherin expression both at transcriptional and post-transcriptional level and that their expression is beneficial for invasiveness. We also proved that Notch1 and E-Cadherin protein expression positively correlates in human HCCs and those patients with high Notch1 and E-Cadherin expression show shorter time to recurrence (TTR). Finally, we uncovered that the lack of Notch1 expression could inhibit tumor's development in vivo contributing to the "field effect".

\section{RESULTS}

\section{Quantitative proteomic analysis reveals changes of protein expression in media of Notch1 depleted cells compared to control cells}

Media from HepG2 control cells and Notch1 depleted cells were investigated for differences in secreted proteins that could be associated to Notch1 expression. Using a gel free proteomic approach and high-resolution mass spectrometry a total of 89 proteins were significantly altered $(P<0.05)$, with 37 proteins up-regulated and 52 down-regulated in Notch1 depleted cells. The list of upregulated and down-regulated proteins is shown in Tables 1 and 2. According to SignallP, secreted proteins represent $37 \%$ of the identified proteins. However to elucidate if proteins could use alternative secretion pathways, each protein was analyzed with SecretomeP. Remarkably 25\% of proteins showed an NN-score of $>0.5$, which predicts non signal peptide-triggered protein secretion and correlates with a non-classical protein secretion pathway. Among the 89 identified proteins, we also detected plasma membrane proteins $(10 \%)$ and intracellular proteins $(18 \%)$, presumably from dead cells (Figure 1A).

\section{Biological function and pathway analysis for deregulated proteins}

To identify altered biological functions that might be associated to Notch1 expression, secreted proteins were classified using DAVID functional annotation tool (Table 3). Cytoskeleton organization, cell adhesion and regulation of cellular protein metabolic process were among the top altered functions with $p$ values ranging from $2.1 \mathrm{E}-05$ to 3.3E- -05 .

\section{Western blot confirms that key protein expression changes in Notch1 depleted cells}

Global quantitative proteomic analysis identified the expression changes of a large number of proteins in Notch1 depleted cells. To confirm that some of these expressions change, we selected several proteins for validation by immunoblotting including Serpinb5 (Pai3), Icam5, Thrombospondin-1 (Thbs1) whose roles are well established in cancer. Remarkably, these proteins are involved in all the significantly altered pathways (Table 3). mTor was used as a control because it has been described as a Notch1 target [18]. Soluble E-Cadherin (sE-Cad) was not detected in proteomic analysis, presumably due to a non-efficient protein extraction. Given the high relevance of sE-Cad to tumor progression [19], it was also assayed by western blot. As shown in Figure 1B cleaved sE-Cad expression was down-regulated in Notch1 depleted cells. Increased expressions of Pai3 and Icam5 and decreased expression of $\mathrm{mTor}$ were also validated.

Conversely, western blot results did not confirm the MS quantification data for Thbs1 that results more expressed in Notch1 depleted cells compared to negative control. In human, five genes with strong homology encoding Thbs 1 through Thbs 5 have been identified [20]. Probably, the high homology of THBS genes makes it difficult to distinguish them by mass spectrometry, which explains the opposite results obtained by western blot and MS.

\section{Thbs1 and sE-Cad are candidate biomarkers to discriminate patients with HCC from controls}

One of the goals of this study was to identify serum biomarkers of propensity towards tumor response 
Table 1: List of up-regulated proteins in the conditioned media associated to Notch1

\begin{tabular}{|c|c|c|c|c|}
\hline IPI Number & Gene Symbol & Protein name & $\begin{array}{c}\text { N1/ } \\
\text { CTRL }\end{array}$ & Score \\
\hline IPI00166060 & LGI4 & Isoform 1 of Leucine-rich repeat LGI family member 4 & 9999 & 0,9784 \\
\hline IPI00888255 & LOC100291104 & hypothetical protein XP_002346815 & 9999 & 0,9643 \\
\hline IPI00902507 & ADAM5P & $\begin{array}{l}\text { Putative disintegrin and metalloproteinase domain- } \\
\text { containing protein } 5\end{array}$ & 9999 & 0,968 \\
\hline IPI00304086 & CTCFL & Transcriptional repressor CTCFL variant B1 & 9999 & 0,9537 \\
\hline IPI00184848 & $\mathrm{ABCB} 11$ & Bile salt export pump & 9999 & 0,9653 \\
\hline IPI00026307 & $\mathrm{CDC} 40$ & Pre-mRNA-processing factor 17 & 9999 & 0,9701 \\
\hline IPI00016690 & LATS2 & Serine/threonine-protein kinase LATS2 & 9999 & 0,9878 \\
\hline IPI00853031 & MRPL23 & Uncharacterized protein & 9999 & 0,9537 \\
\hline IPI00012048 & NME2;NME1 & Nucleoside diphosphate kinase A & 9999 & 0,9745 \\
\hline IPI00026327 & Not provided & $134 \mathrm{kDa}$ protein & 9999 & 0,9529 \\
\hline IPI00025363 & GFAP & Isoform 1 of Glial fibrillary acidic protein & 9999 & 0,964 \\
\hline IPI00021146 & PRPF18 & Isoform 1 of Pre-mRNA-splicing factor 18 & 9999 & 0,9545 \\
\hline IPI00021727 & C4BPA & C4b-binding protein alpha chain & 10,997 & 0,9784 \\
\hline IPI00953689 & AHSG & Alpha-2-HS-glycoprotein & 10,776 & 1 \\
\hline IPI00554648 & KRT8 & Keratin, type II cytoskeletal 8 & 10,202 & 0,968 \\
\hline IPI00401829 & C14orf38 & Uncharacterized protein C14orf38 & 8,459 & 0,9701 \\
\hline IPI00844508 & CGN & Cingulin & 7,104 & 1 \\
\hline IPI00219563 & PLCB1 & $\begin{array}{l}\text { Phosphatidylinositol-4,5-bisphosphate phosphodiesterase } \\
\text { beta-1 }\end{array}$ & 6,449 & 0,964 \\
\hline IPI00002993 & TAF9 & Transcription initiation factor TFIID subunit 9 & 5,613 & 1 \\
\hline IPI00397016 & FOXO6 & Forkhead box protein $\mathrm{O} 6$ & 5,207 & 0,9784 \\
\hline IPI00012011 & CFL1 & Cofilin-1 & 4,808 & 0,9924 \\
\hline IPI00001895 & PCDH8 & Isoform 1 of Protocadherin- 8 & 4,223 & 0,9548 \\
\hline IPI00220644 & PKM2 & Isoform M1 of Pyruvate kinase isozymes M1/M2 & 4,071 & 1 \\
\hline IPI00795830 & AHSG & Uncharacterized protein & 3,114 & 1 \\
\hline IPI00306322 & COL4A2 & Collagen alpha-2(IV) chain & 3,092 & 0,968 \\
\hline IPI00290456 & ICAM5 & Intercellular adhesion molecule 5 & 2,928 & 0,9784 \\
\hline IPI00032258 & $\mathrm{C} 4 \mathrm{~A}$ & Complement C4-A & 2,821 & 1 \\
\hline IPI00027497 & GPI & Glucose-6-phosphate isomerase & 2,73 & 1 \\
\hline IPI00021754 & $44 \mathrm{M} 2.3$ & Isoform 2 of Putative RNA exonuclease NEF-sp & 2,728 & 0,9537 \\
\hline IPI00007221 & SERPINA5 & Plasma serine protease inhibitor & 2,674 & 1 \\
\hline
\end{tabular}




\begin{tabular}{|l|l|l|c|c|}
\hline IPI00217963 & KRT16 & Keratin, type I cytoskeletal 16 & 2,577 & 0,968 \\
\hline IPI00005690 & MATN3 & Matrilin-3 & 2,498 & 0,9878 \\
\hline IPI00887739 & Not provided & Uncharacterized protein & 2,441 & 1 \\
\hline IPI00021885 & FGA & Isoform 1 of Fibrinogen alpha chain & 2,418 & 1 \\
\hline IPI00008787 & NAGLU & Alpha-N-acetylglucosaminidase & 2,286 & 0,9545 \\
\hline IPI00794873 & Not provided & Uncharacterized protein & 2,221 & 0,9956 \\
\hline IPI00026260 & NME2;NME1 & Isoform 1 of Nucleoside diphosphate kinase A & 2,029 & 1 \\
\hline
\end{tabular}

Table 2: List of Down-regulated proteins in the conditioned media associated to Notch1

\begin{tabular}{|c|c|c|c|c|}
\hline IPI Number & Gene Symbol & Protein name & N1/CTRL & Score \\
\hline IPI00514893 & DAAM2 & Disheveled-associated activator of morphogenesis 2 & -9999 & 0,9537 \\
\hline IPI00644712 & XRCC6 & $\mathrm{X}$-ray repair cross-complementing protein 6 & -9999 & 0,9784 \\
\hline IPI00029723 & FSTL1 & Follistatin-related protein 1 & -9999 & 0,9745 \\
\hline IPI00216298 & TXN & Thioredoxin & -9999 & 1 \\
\hline IPI00006608 & APP & Isoform APP770 of Amyloid beta A4 protein (Fragment) & -9999 & 1 \\
\hline IPI00021000 & SPP1 & Osteopontin isoform $\mathrm{b}$ precursor & -9999 & 1 \\
\hline IPI00168866 & MDGA1 & $\begin{array}{l}\text { MAM domain-containing glycosylphosphatidylinositol } \\
\text { anchor protein } 1\end{array}$ & -9999 & 0,9701 \\
\hline IPI00027547 & DCD & Dermcidin & -9999 & 0,9722 \\
\hline IPI00290358 & C16orf91 & Chromosome 16 open reading frame 91 & -9999 & 0,9653 \\
\hline IPI00003802 & MAN2A1 & Alpha-mannosidase 2 & -9999 & 0,9537 \\
\hline IPI00164352 & ZNF292 & Isoform 1 of Zinc finger protein 292 & -9999 & 0,9745 \\
\hline IPI00430472 & $\mathrm{ASCC} 3$ & Activating signal cointegrator 1 complex subunit 3 & -9999 & 0,9797 \\
\hline IPI00297859 & MLL2 & Isoform 1 of Histone-lysine N-methyltransferase MLL2 & -9999 & 0,9537 \\
\hline IPI00002804 & PKN2 & Serine/threonine-protein kinase N2 & -9999 & 0,9722 \\
\hline IPI00007193 & ANKRD26 & $\begin{array}{l}\text { Isoform } 2 \text { of Ankyrin repeat domain-containing protein } \\
26\end{array}$ & -9999 & 0,9745 \\
\hline IPI00220827 & TMSB10 & Thymosin beta- 10 & -9999 & 0,9701 \\
\hline IPI00412694 & ANO5 & Anoctamin-5 & -9999 & 0,9797 \\
\hline IPI00142538 & SETX & Isoform 1 of Probable helicase senataxin & -9999 & 0,9646 \\
\hline IPI00375578 & SASS6 & Spindle assembly abnormal protein 6 homolog & -9999 & 0,9722 \\
\hline IPI00414896 & RNASET2 & Isoform 1 of Ribonuclease $\mathrm{T} 2$ & -9999 & 0,9784 \\
\hline IPI00021812 & AHNAK & $\begin{array}{l}\text { AHNAK Neuroblast differentiation-associated protein } \\
\text { AHNAK }\end{array}$ & -9999 & 0,9745 \\
\hline IPI00741855 & KRT39 & KRT39 Keratin, type I cytoskeletal 39 & -9999 & 0,9701 \\
\hline IPI00329679 & ZWILCH & Isoform 1 of Protein zwilch homolog & -9999 & 1 \\
\hline
\end{tabular}




\begin{tabular}{|c|c|c|c|c|}
\hline IPI00556369 & SMG1 & $\begin{array}{l}\text { SMG1 Isoform } 3 \text { of Serine/threonine-protein kinase } \\
\text { SMG1 }\end{array}$ & -9999 & 0,9653 \\
\hline IPI00401831 & PLEKHH1 & $\begin{array}{l}\text { Pleckstrin homology domain-containing family } \\
\text { H member } 1\end{array}$ & -9999 & 1 \\
\hline IPI00003818 & KYNU & Kynureninase & -9999 & 0,9701 \\
\hline IPI00013400 & MMP7 & Matrilysin & -9999 & 0,9797 \\
\hline IPI00096066 & SUCLG2 & $\begin{array}{l}\text { Succinyl-CoA ligase [GDP-forming] subunit beta, } \\
\text { mitochondrial }\end{array}$ & -9999 & 0,9537 \\
\hline IPI00178352 & FLNC & Isoform 1 of Filamin-C & -9999 & 0,964 \\
\hline IPI00791999 & PSMD9 & $26 \mathrm{~S}$ proteasome non-ATPase regulatory subunit 9 & -9999 & 0,9722 \\
\hline IPI00879906 & Not provided & $92 \mathrm{kDa}$ protein & -9999 & 0,9722 \\
\hline IPI00031410 & MTOR & Serine/threonine-protein kinase mTOR & -9999 & 0,9722 \\
\hline IPI00302927 & CCT4 & complex protein 1 subunit delta & -9999 & 0,9529 \\
\hline IPI00217992 & DST & Isoform 3 of Bullous pemphigoid antigen 1 & 0,023 & 0,95 \\
\hline IPI00291175 & VCL & Isoform 1 of Vinculin & 0,058 & 1 \\
\hline IPI00293878 & CMTM8 & $\begin{array}{l}\text { CKLF-like MARVEL transmembrane domain-containing } \\
\text { protein } 8\end{array}$ & 0,06 & 0,9722 \\
\hline IPI00025252 & PDIA3 & Protein disulfide-isomerase A3 & 0,078 & 0,9797 \\
\hline IPI00219249 & CNTNAP1 & Contactin-associated protein 1 & 0,089 & 0,9722 \\
\hline IPI00789146 & Not provided & $13 \mathrm{kDa}$ protein & 0,103 & 0,9722 \\
\hline IPI00847471 & IGSF9B & IGSF9B Protein turtle homolog B & 0,145 & 0,9722 \\
\hline IPI00883591 & ZNHIT1 & ZNHIT1 Conserved hypothetical protein & 0,17 & 0,9722 \\
\hline IPI00009852 & ATP6V0A4 & Proton ATPase $116 \mathrm{kDa}$ subunit a isoform 4 & 0,234 & 0,9537 \\
\hline IPI00180408 & MYH15 & Myosin-15 & 0,271 & 1 \\
\hline IPI00296099 & THBS1 & THBS1 Thrombospondin-1 & 0,283 & 1 \\
\hline IPI00935923 & LOC100286949 & hypothetical protein XP_002342730 & 0,303 & 0,9548 \\
\hline IPI00072377 & SET & Isoform 1 of Protein SET & 0,314 & 0,9924 \\
\hline IPI00218319 & TPM3 & Isoform 2 of Tropomyosin alpha-3 chain & 0,317 & 1 \\
\hline IPI00400826 & CLU & Isoform 1 of Clusterin & 0,399 & 1 \\
\hline IPI00013256 & CSTF2 & Isoform 1 of Cleavage stimulation factor subunit 2 & 0,411 & 0,9537 \\
\hline IPI00385149 & PTMA & Putative uncharacterized protein & 0,412 & 1 \\
\hline IPI00103381 & IPCEF1 & $\begin{array}{l}\text { Isoform } 2 \text { of Interactor protein for cytohesin exchange } \\
\text { factors } 1\end{array}$ & 0,433 & 0,964 \\
\hline IPI00008529 & RPLP2 & $60 \mathrm{~S}$ acidic ribosomal protein $\mathrm{P} 2$ & 0,49 & 1 \\
\hline
\end{tabular}

to Notch1 inhibitors as well as of indicators of treatment efficacy. Proteins found to be related to Notch1 expression in cell culture medium were analyzed in serum of patients with cirrhosis, early HCC, advanced HCC or healthy controls (Figure 1C). All the analyzed proteins have been identified in serum. Among the deregulated proteins Pai3, sE-Cad and Thbs 1 significantly discriminated patients from controls whereas sE-Cad and Icam5 showed the ability to 
discriminate early from advanced HCCs (Figure 1C). Thbs1, sE-Cad and Icam5 deserve attention in future studies as noninvasive biomarkers of response to Notch1 inhibitors.

\section{Thbs1 serum levels negatively correlates with Notch1 expression in human HCC}

Notch1 expression was evaluated by immunohistochemistry in 18 early HCCs of which we also had serum. A significant inverse correlation was determined between Notch1 and Thbs1 serum levels evaluated by ELISA (Pearson's test: $p<0.05$ ) (Supplementary Figure 1) confirming a role of Notch1 in the regulation of Thbs1.

\section{Targeting Notch1 decreases HCC cells invasion in vitro}

To clarify the role of Notch1 in the context of HCC we employed HepG2, SNU398 and SNU449 cells as in vitro models. The nuclear localization of NICD (Notch Intracellular Domain) suggests the activation of the receptor in the analyzed cell lines (Supplementary Figure 2A). According to this last remark, the expression of HES1 and CYCLIN D1 target genes is down- regulated in response to Notch1 stable silencing (Supplementary Figure 2B).

Compared with control cells Notch1 KD cells underwent significant morphologic changes, which included a larger, flattened phenotype and tighter, more numerous cell-cell contacts (Figure 2B). Moreover, Notch1 silenced cells showed a low level of penetration through the matrigel-coated membrane, decreased Mmp-9 activity and reduced capacity to migrate into the wound area compared with the NC-infected cells (Figure 2C-2E). Additionally numerous mesenchymal related proteins including Keratin 19 (Ck19), Vimentin, Snail, Alpha-Sma and Mmp-9 were significantly down-regulated whereas epithelial markers including Keratin 8 and E-Cadherin resulted up-regulated and down-regulated respectively (Figure 2A). To confirm an E-Cadherin down-regulation in N1 silenced HepG2 cells we performed immunocytochemistry. As shown in Figure 3A NC cells demonstrated a more abundant E-Cadherin expression with a cell surface pattern than Notch1 depleted cells. Conversely, semi-quantitative RT-PCR analysis revealed an increased expression of E-Cadherin in N1 silenced cells compared to negative control (Supplementary Figure 2B) in line with Snail reduction suggesting that Notch1 regulates E-Cadherin levels in HCC by transcriptional and post-transcriptional mechanisms. Gene expression of N-CADHERIN, SNAIL, TWIST and VIMENTIN were also analysed. No difference was observed for all these genes following Notch1 downregulation (Supplementary Figure 2B). We previously showed that Notch1 down-regulation does not affect cell viability but reduces cell proliferation [21]. To rule out that the inhibitory effects of Notch1 down-regulation on cell migration were not a consequence of reduced cell growth, the expression of the proliferation marker Ki-67 was analysed on wound-healing assay. The analysis was
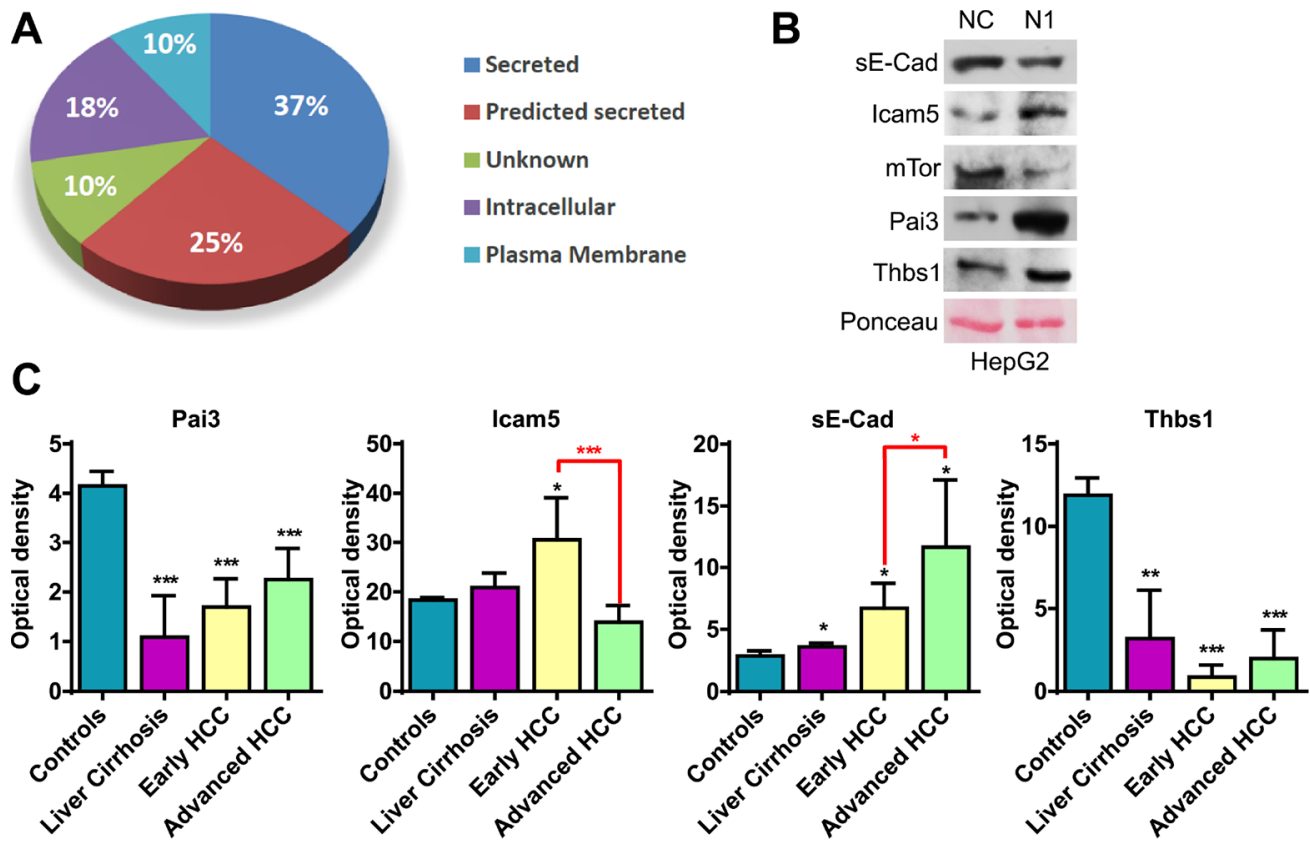

Figure 1: Analyses of secreted proteins. (A) Subcellular localization of significantly altered proteins associated to Notch1 expression. (B) Western blot analysis confirms changes in protein expression in Notch1 depleted cells. Ponceau serves as proteins loading control. NC: negative control shRNA; N1: Notch1 shRNA. (C) Proteins found to be related to Notch1 expression in cell culture medium were analyzed in serum sample from patients with liver cirrhosis, early HCC, advanced HCC or healthy controls. Statistical analysis was performed by comparing patients to healthy controls (black asterisk) or by comparing early vs. advance HCCs (red asterisk) ${ }^{*} P<0.05$; $* * P<0.01$; $* * * P<0.001$ (by two tailed student's $t$ test). 
Table 3: Biological function

Gene Symbol

Regulation of organelle organization

CTCFL

SET

CFL1

DST

MTOR

TMSB10

Cytoskeleton organization

CFL1

DAAM2

DST

KRT16

KRT8

SASS6

TMSB10

Cell adhesion

APP

CNTNAP1

DST

ICAM5

NME1-NME2

PCDH8

THBS1

VCL

Regulation of cellular metabolic process

CTCFL

SET

TAF9

APP

MTOR

SERPINA5

THBS1

Membrane Organization

AHSG

APP

ICAM5

NME1-NME2

SERPINA5

THBS1

Endocytosis

\section{$P$ Value}

$9,80 \mathrm{E}-06$

$2,10 \mathrm{E}-05$

$2,80 \mathrm{E}-05$

$3,30 \mathrm{E}-05$

$1,40 \mathrm{E}-04$

$2,20 \mathrm{E}-04$ 


\begin{tabular}{|c|c|}
\hline AHSG & \\
\hline APP & \\
\hline ICAM5 & \\
\hline NME1-NME2 & \\
\hline THBS1 & \\
\hline Regulation of cellular component size & $4,80 \mathrm{E}-04$ \\
\hline TAF9 & \\
\hline APP & \\
\hline CFL1 & \\
\hline MTOR & \\
\hline TMSB10 & \\
\hline SPP1 & \\
\hline Response to organic substance & $2,60 \mathrm{E}-03$ \\
\hline LATS & \\
\hline TAF9 & \\
\hline AHSG & \\
\hline CFL1 & \\
\hline KYNU & \\
\hline MTOR & \\
\hline NME1-NME2 & \\
\hline SPP1 & \\
\hline THBS1 & \\
\hline Vesicle mediated transport & $7,60 \mathrm{E}-03$ \\
\hline AHSG & \\
\hline APP & \\
\hline ICAM5 & \\
\hline NME1-NME2 & \\
\hline THBS1 & \\
\hline Cell death & $2,30 \mathrm{E}-02$ \\
\hline TAF9 & \\
\hline CLU & \\
\hline CFL1 & \\
\hline NME1-NME2 & \\
\hline THBS1 & \\
\hline Phospate metabolic process & $4,30 \mathrm{E}-02$ \\
\hline LATS2 & \\
\hline SMG1 & \\
\hline APP & \\
\hline CFL1 & \\
\hline MTOR & \\
\hline NME1 & \\
\hline PKN2 & \\
\hline THBS1 & \\
\hline
\end{tabular}


performed on SNU449 cells that are highly proliferating and have a high ability to penetrate through the matrigelcoated membrane. In the wound area we found both positive and negative cells for Ki67 protein expression suggesting that migration is not affected by cell proliferation (Supplementary Figure 3A).
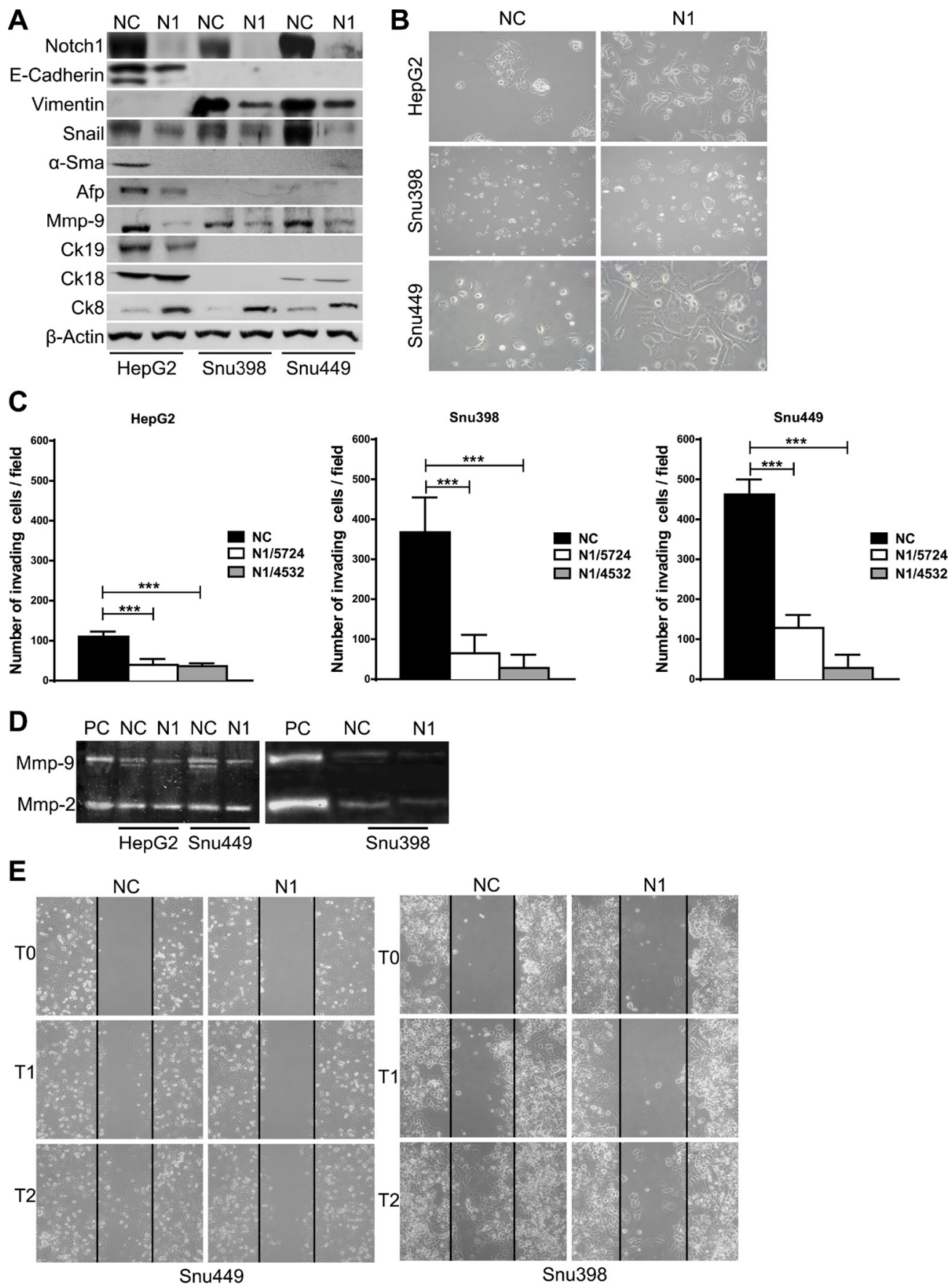

Figure 2: Effect of Notch1 knockdown. (A) Proteins expression analysis in negative control cells and in Notch1 silenced cells by western blot. (B) Morphology of negative control shRNA and Notch1 depleted cells. (C) Difference in invasiveness ability of negative control cells and Notch1 silenced cells. ShOligos targeted to different Notch1 exons were used (N1/5724 and N1/4532). Results are the mean of three independent experiments (+/- S.E.). ${ }^{* * *} P<0.001$ (by two tailed student's $t$ test). (D) Zymographic analysis of the Mmp-9 and Mmp-2 activity. PC: positive control. (E) Wound healing assay demonstrates that there are significantly more negative control cells that migrate into the wound area compared with Notch1 silenced cells. NC: negative control shRNA; N1: Notch1 shRNA. 


\section{Notch1 and E-Cadherin contribute to the invasion of $\mathrm{HCC}$}

To determine if the reduced E-Cadherin levels were functionally associated with lower capacity to invade of Notch1 KD cells, HepG2 cells were transfected with human E-Cadherin siRNA (Figure 3B) and matrigel invasion assay was used to examine the invasive potential of E-Cadherin silenced cells. As illustrated in Figure 3C, E-Cadherin siRNA transfected cells showed a low level of penetration through the matrigel-coated membrane compared with cells transfected with the control siRNA. Interestingly, secreted proteins regulated by Notch1 were not affected by E-Cadherin inhibition with the exception of Pai3 suggesting that Notch1 and E-Cadherin (Figure 3B) regulate different pathways.

To further confirm the role of E-Cadherin in cell invasion, E-Cadherin was over-expressed in SNU398 Notch1 KD and in NC control cells (Figure 3D). E-Cadherin expression resulted in higher penetration of $\mathrm{NC}$ cells through the matrigel-coated membrane compared with the control pcmv-transfected cells (Figure 3E). Overexpression of E-Cadherin reverted effects of Notch1 ablation on cell motility in SNU398 cells. The same result was obtained in HepG2 Notch1 depleted cells following the re-expression of E-Cadherin. Our data shows an additive effect of Notchl and E-Cadherin on invasion meaning the cells that do not express E-Cadherin take more advantage from Notch1 silencing. Indeed reduced cell migration was more evident in SNU398 and SNU449 than in HepG2 cells upon Notch1 silencing (Figure 2C). In agreement with this observation, several recent studies describe E-Cadherin re-expression in advanced metastatic tumors [22]. Furthermore, knockdown of E-Cadherin in the Notch depleted mammalian intestinal stem cells tumor resulted in strong suppression of cell mass formation [23].

\section{Notch1 and E-Cadherin protein levels correlate in human $\mathrm{HCC}$}

To assess whether our in-vitro findings reflect the biology of human HCC, Notch1 and E-Cadherin protein expression were analysed in 38 surgically resected HCCs by western blots.

A significant positive correlation between Notch1 and E-Cadherin proteins accumulation was found (Pearson's test: $p<0.01$ ) (Figure 4A). $\mathrm{HCC}_{\mathrm{s}}$ were dichotomized based on Notch1 and E-Cadherin expression and the cut-off values were chosen based on median values in the whole series of HCC tissues. Both high Notch1 and E-Cadherin levels in $\mathrm{HCC}$ tissue were associated with shorter time to recurrence (TTR) (Figure 4B-4C).

\section{Notch1 expression in liver is associated with HCC development}

To further confirm the potential role of Notch1 in the increased risk of $\mathrm{HCC}$ recurrence, we analysed its
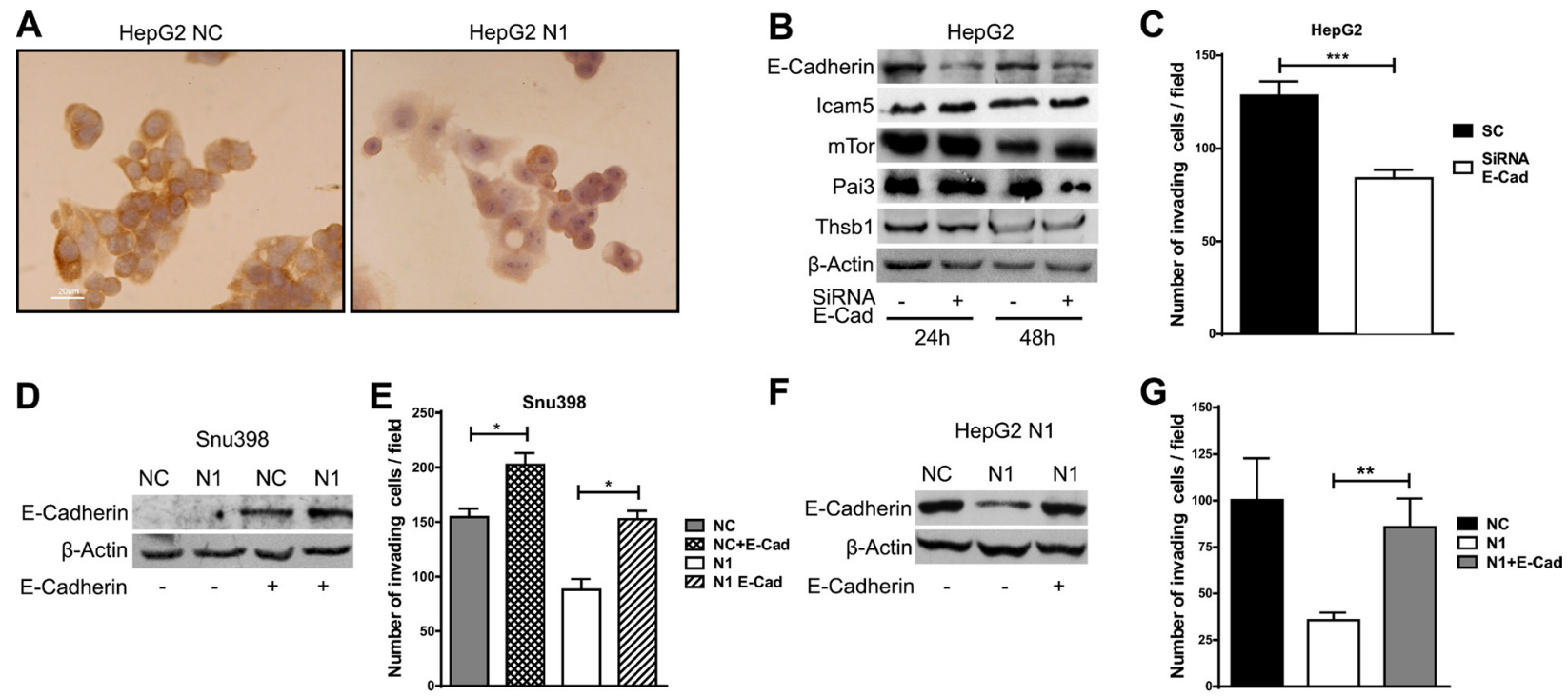

Figure 3: E-Cadherin induces invasion in hepatocellular carcinoma. (A) Expression and subcellular localization of E-Cadherin, as detected by the immunoperoxidase method in HepG2 cell line. Positive staining was observed in cell membranes. Nuclei were counterstained with hematoxylin. Original magnification 40X. NC: negative control shRNA; N1: Notch1 shRNA. (B) HepG2 cells were transfected with E-Cadherin siRNA (E-Cad) or scrambled RNA and proteins expression analysis was evaluated $24 \mathrm{~h}$ and $48 \mathrm{~h}$ post-transfection by western blot. (C) Difference in invasiveness ability of HepG2 control cells and E-Cad silenced cells evaluated $48 \mathrm{~h}$ post-transfection. Results are the mean of three independent experiments $(+/-$ S.E.). $* * * P<0.001$ (by two tailed student's $t$ test). (D-G) SNU398 and HepG2 cells stable silenced for Notch1 (N1) and negative control (NC) were transfected with E-Cadherin expressing vector or with empty vector and difference in invasiveness ability was evaluated. Results are the mean of three independent experiments $(+/-$ S.E.) $* P<0.05 ; * P<0.01$ (by two tailed student's $t$ test). 
expression in cirrhotic liver tissue surrounding HCC by western blot. Notch1 expression in cirrhotic tissues was higher in patients with low ( $<2$ years) vs. high $(>2$ years) recurrence-free survival. On the contrary, no difference is observed in the expression of E-Cadherin between the two groups (Figure 5A-5B). These data suggest that Notch1 deserves attention as candidate for personalized therapies in the prevention of $\mathrm{HCC}$ recurrence after curative surgery.

Two distinct types of HCC recurrence are known: tumor grown from dissemination of the primary tumor and de novo tumor arising from "the field effect" in diseased liver [24]. The field effect is a carcinogenic microenvironment, which is assumed to cause accumulated genetic hits inducing cellular transformation [25].

To examine the possible involvement of Notch1 in generating this carcinogenic microenvironment we used the DENA model of liver carcinogenesis in rats [26]
(Supplementary Figure 4). Animals were treated with DENA for 8 weeks and then monitored by ultrasound for HCC development. Tumor's growth was observed in $88 \%$ of rats whereas HCC was not detected among the remaining rats. Since the overt tumors cannot be considered as early lesions, we assessed the contribution of Notch1 to the "field effect" of non-tumor liver tissue. Indeed, HCC outcome can be predicted using non-tumor liver tissue as previously reported [24]. Interestingly, western blot analysis showed higher Notch1 expression in the non-tumor liver of rats that developed HCC nodules compared to those that did not develop tumors (Figure 5D) suggesting a role of Notch1 in HCC development.

In agreement with the results in human cirrhosis, no differences were observed in the levels of E-Cadherin between the two groups (Figure 5E).
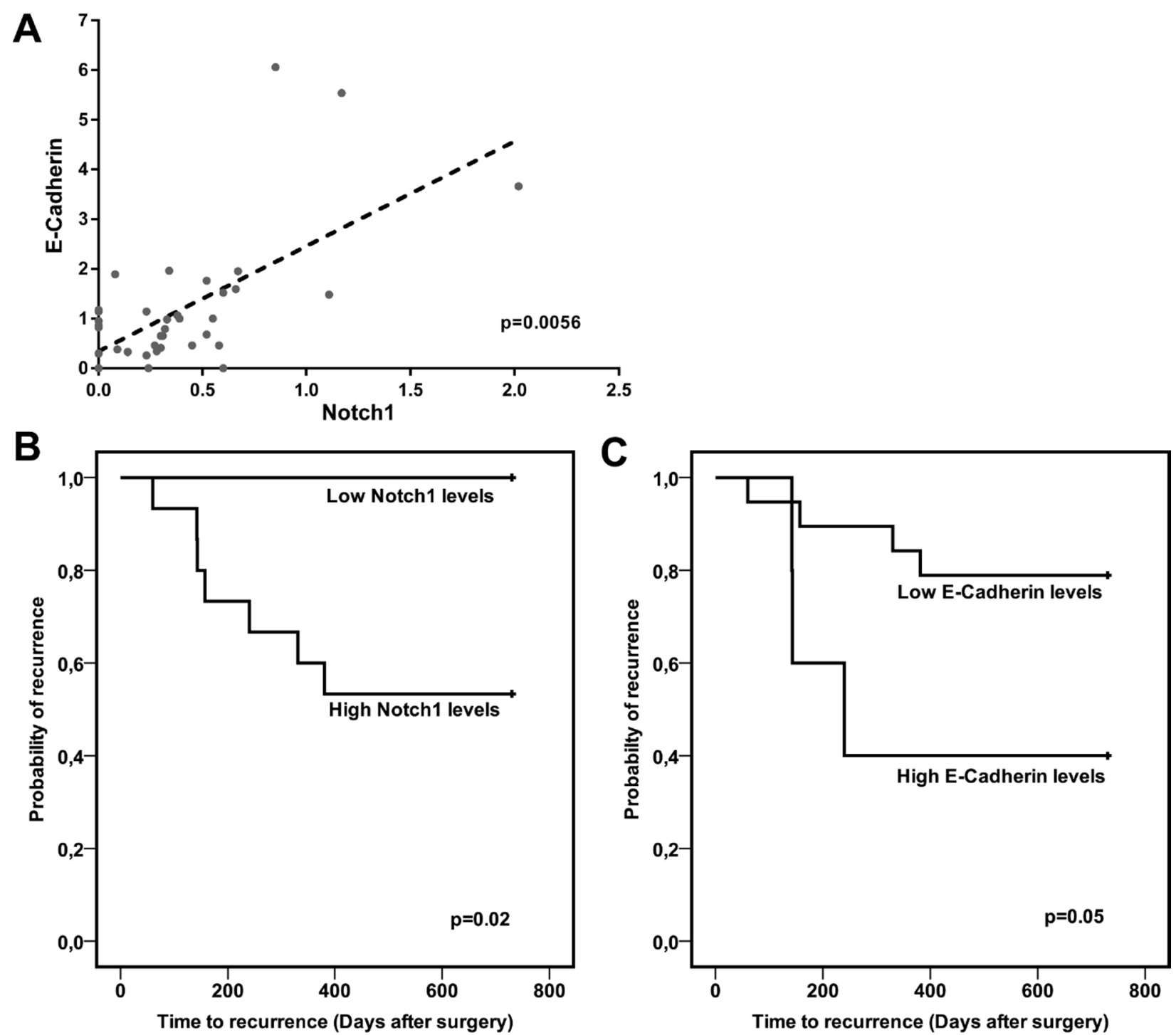

Figure 4: Notch1 and E-Cadherin correlate in human HCC and predict TTR. (A) Scatter plot showing the relationship between Notch1 and E-Cadherin protein expression in 38 studied human HCCs. $P=0.0056$ (by two tailed student's $t$ test). (B-C) Association between Notch1 and E-Cadherin levels and TTR of surgically resected HCC patients. High and low, Notch1 and E-Cadherin expressions were categorized according to the mean value. Data on TTR were missing in 14 cases. Log-rank $P$ values were from Kaplan-Meier analysis. 


\section{DISCUSSION}

In an effort to bring scientific knowledge from the bench to the bedside, several anti-Notch1 agents are under investigation [27] and it's of important interest to identify molecular biomarkers that can be used to predict tumor response or resistance to therapy. In this study, we used a proteomic approach comparing HepG2 and HepG2 Notch1 depleted cells to identify potential proteins biomarkers for predicting the efficacy of Notch1 inhibition. Quantitative proteomic analysis revealed changes in 89 proteins resulting from Notch1 silencing. Many of the identified proteins were initially classified as non-secreted, but further analysis revealed that they could use non-conventional secretion pathways. Similar findings were described for the secretome of other cancer cell lines [28]. They could be exosomal proteins, proteins cleaved from plasma membrane or derived from cellular breakage. We focused on proteins reported to be relevant in different pathways including cell adhesion, membrane organization and regulation of metabolic process. Due to keratins expression in some normal human tissues and in different diseases their serum levels might be modulated by health conditions in patients and were not validated [29]. After testing different proteins, Pai3, Thbs1 and sE-Cad show the ability to discriminate patients from controls whereas Icam5 and sE-Cad categorize early from advanced HCCs. In line with our results showing higher serum levels of sE-Cad in advanced HCC compared to early HCC, sE-Cad was associated to recurrence or extrahepatic metastasis [30]. Thbs1 is considered an angiogenesis inhibitor associated to tumor invasion in melanoma, lung cancer, breast cancer and cholangiocarcinoma [31-33]. Accordingly, with our results, Thbs1 expression was reduced in HCC tissue compared with non-cancerous tissue [34].

Although validation using a larger sample set is required, our results provide evidence that Pai3, Thbs1, and sE-Cad could be promising serum biomarkers to predict response to Notch1 inhibitors, also based on the negative correlation between the expression of Notch1 in HCCs and serum Thbs1 levels evaluated by ELISA.

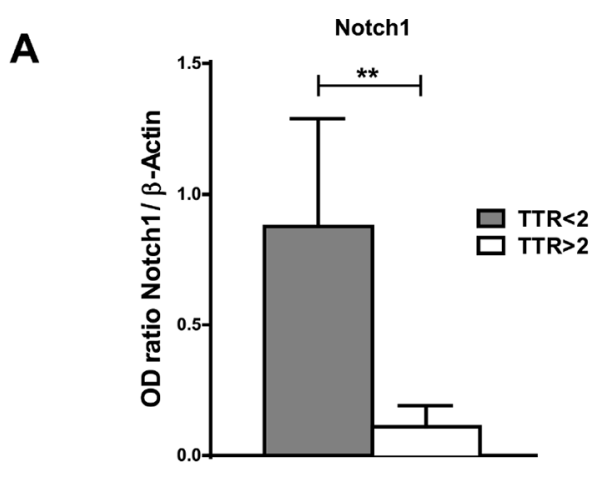

D
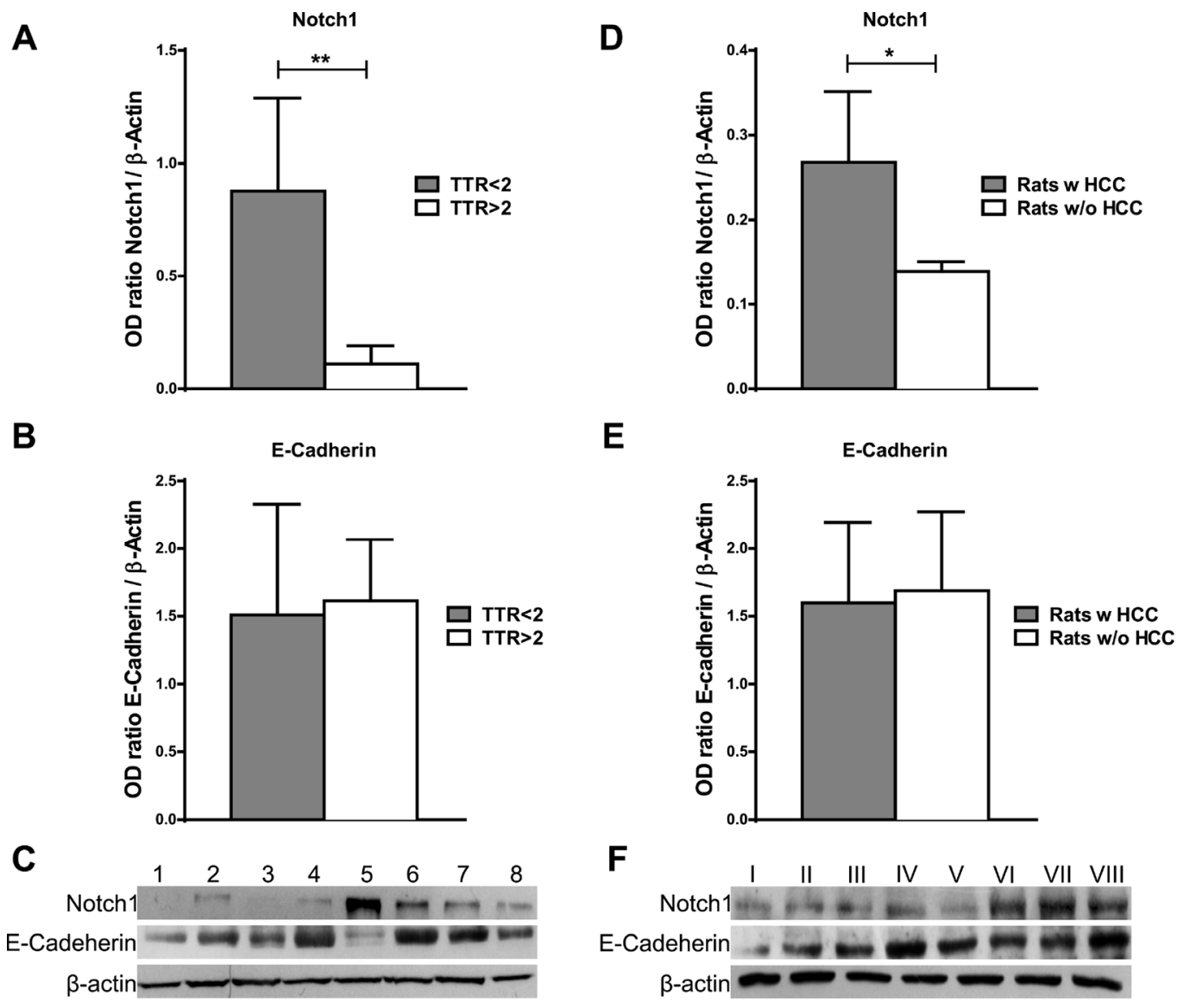

Figure 5: Notch1 and E-Cadherin expression in non-tumor liver tissue. (A-B) Notch1 and E-Cadherin expression were evaluated by western blot in cirrhotic tissues surrounding HCC and a higher Notch1 expression was observed in cases with poor $(<2$ years) vs. good ( $>2$ years) recurrence-free survival (TTR) $* * P<0.01$ (by two tailed student's $t$ test). (C) Representative Notch1 and E-Cadherin expression in cirrhotic tissues with poor ( $<2$ years) (cases 5-8) vs. good ( $>2$ years) (cases 1-4) recurrence-free survival (D-E) Notch1 and E-Cadherin protein expressions were detected by western blot in liver of rats treated with DENA. Higher Notch1 expression was observed in non-tumor liver of rats that developed HCC (Rats w HCC) compared to those that did not developed (Rats w/o HCC). * $P<0.05$ (by two tailed student's $t$ test). (F) Representative Notch1 and E-Cadherin expressions in non-tumor liver of rats that developed HCC (cases V-VIII) compared to those that did not developed HCC (I-IV). 
Recent evidences suggest that Notch1 is also associated with recurrence after surgery in human malignancies [35]. Surgery is the standard of care for patients with resectable HCC [36] however, long-term prognosis remains poor due to high recurrence rate associated with both dissemination of the primary HCC and de novo tumors arising from the 'field effect' in the diseased liver [37]. Herein we show that Notch1 promotes the invasion capabilities of HCC cells. To explore the potential mechanism involved in this process, we found out that down-regulated Notch1 cells reduce E-Cadherin protein expression. E-Cadherin has been identified as a tumor suppressor in different human cancer; however, several studies suggest that the role of E-Cadherin might be more complex [38]. E-Cadherin expression has been described to favor invasiveness and intra-hepatic metastases in some studies $[39,40]$ while others reported opposed results in HCC [9] suggesting that environmental factors are also involved in the routes of Hepatocellular carcinoma development. Herein we showed that siRNA mediated E-Cadherin knockdown reduces invasion capability of HepG2 cells. Interestingly, in down-regulated Notch1 cells, E-Cadherin over-expression reverted effect of Notch1 ablation on cellular invasion suggesting that both Notch1 and E-Cadherin contribute to invasion in HCC. In agreement with the in vitro data, TTR was shorter in patients displaying high levels of both Notch1 and E-Cadherin protein expression. On the contrary, the expression of E-Cadherin in cirrhosis cannot be considered as marker of early recurrence.

Finally to examine the possible involvement of Notch1 in generating a microenvironment responsible for the "the field effect" in diseased liver we used the DENA model of liver carcinogenesis in rats. We found out that Notch1 was expressed in the non-tumor liver of rats that developed HCC while it was not expressed in the liver of rats that did not develop hepatocellular carcinoma, suggesting that the lack of Notch1 protein expression could prevent HCC development. According to our observation, Notch1 increased during the hepatocarcinogenesis process induced by the methyl-deficient diet in rat liver [41]. Moreover, Notch1 signaling promotes liver carcinogenesis in a genetically engineered mouse model [42]. On the other hand, Huntzicker and coauthors described that Notch1 inhibition altered the relative proportion of tumor types, reducing HCC-like tumors but dramatically increasing cholangiocarcinoma-like tumors [16]. This is not surprising given that Notch signaling can play opposite biological effects that are highly context-specific in a time, gene-dose and cell type dependent manner [43].

In line with the results in human cirrhosis, the expression of E-Cadherin is similar in rats that developed HCC compared to those that did not develop cancer. Overall, our results suggest that the expression of E-Cadherin is a late event in the development and progression of cancer.
In conclusion, in this study we showed that Notch 1 expression correlates with both tumor development and recurrence making Notch1 a good candidate for targeted therapies in HCC. Furthermore, Pai3, sE-Cad and Thbs 1 can be used as serum markers of susceptibility to Notch1 inhibitors.

\section{MATERIALS AND METHODS}

\section{Ethics statement}

Investigation has been conducted in accordance with the ethical standards according to the Declaration of Helsinki and according to national and international guidelines and has been approved by the author's institutional review board.

\section{Cell lines and Notch1 knockdown by retroviral transduction of shRNAs}

The human hepatocarcinoma cell lines HepG2, SNU398 and SNU449 were obtained from American Type Culture Collection (ATCC, Rockville, MD, USA) maintained in Media according to ATCC instructions. Notch1 knock down (KD) was obtained using short hairpin oligonucleotides (ShOligos) targeted to different Notch1 exons inserted into the pSuper.puro expression vector (OligoEngine, Seattle, WA) as previously described [13]. Since two Notch1 specific shRNAs were equally effective in our previous study [13] and here in the invasion assay, we performed the experiments by selecting a single shRNA (N1). Cells harbouring a pSuper.puro provirus expressing a GL2 luciferase specific shRNA were used as negative control (NC).

\section{Cell culture and conditioned media (CM)}

HepG2 Notch1 silenced cells and GL2 control cells were cultured to $80 \%$ confluence in the medium as above described. Plated cells were washed 5 times with PBS and incubated in FBS-free media for $24 \mathrm{~h}$ at $37^{\circ} \mathrm{C}$. At the end of the culture period, $\mathrm{CM}$ was removed and centrifuged at $1,500 \mathrm{rpm}$ for $5 \mathrm{~min}$. The supernatant was transferred into fresh tubes and a mixture of phosphatase and protease inhibitors was added. The CM was concentrated using acetone and protein concentration was determined using the Bio-Rad protein assay (Bio-Rad).

\section{Trypsin digestion}

Twelve $\mu \mathrm{g}$ of protein extract was treated with $5 \mu$ of ammonium bicarbonate (AMBIC) $100 \mathrm{mM}$, reduced with dithiothreitol (DTT, $10 \mathrm{mM}, 1 \mu \mathrm{l}$ in AMBIC $100 \mathrm{mM}$ ) at $56^{\circ} \mathrm{C}$ for $30^{\prime}$ and alkylated with 4-vinyl pyridine $(55 \mathrm{mM}$, $1 \mu \mathrm{l}$ in AMBIC $100 \mathrm{mM}$ ) at room temperature (RT) in the 
dark for $1 \mathrm{~h}$. Alkylating agent excess was quenched with $10 \mu \mathrm{l}$ DTT $10 \mathrm{mM}$ which was left reacting at RT for 10'. The resulting protein mixtures were digested with TPCKmodified sequencing grade trypsin (final ratio of enzyme to substrate $1: 50 \mathrm{w} / \mathrm{w}$ ) at $37^{\circ} \mathrm{C}$ overnight. Samples were then acidified with $5 \%$ formic acid (FA) solution and dried in a vacuum evaporator. Peptides were resuspended in $30 \mathrm{ul}$ of 1\% FA/acetonitrile 98:2 solution.

\section{Mass spectrometry analysis and proteins identification}

Analyses were performed by ESI-Q-TOF AccurateMass G6520AA (Agilent Technologies), controlled by MassHunter (v. B.02.00) and interfaced by a CHIP-cube to an Agilent 1200 nano-pump. Chromatographic separation was performed on a high capacity loading chip, with a $150 \mathrm{~mm}, 300 \AA, \mathrm{C} 18$ column prior to a desalting step through a $500 \mathrm{~nL}$ trap column. Injected sample $(2 \mu \mathrm{l}, 0.8 \mu \mathrm{g})$ was loaded on the trap column with a $4 \mu \mathrm{l} / \mathrm{min} 0.1 \% \mathrm{FA}: \mathrm{ACN}$ 98:2 phase; after $3 \mathrm{~min}$, the precolumn was switched in-line with the nano flow $(400 \mathrm{nl} / \mathrm{min}$, phase A: water:ACN:FA 96.9:3:0.1, phase B: ACN:water:FA 97:3:0,1). The peptides were eluted from the RP column through the following gradient: $3-45 \%$ B over a period of 75 minutes, $45-90 \%$ in $10 \mathrm{~min}, 90 \% \mathrm{~B}$ hold for $5 \mathrm{~min}$, and back to $3 \% \mathrm{~B}$ in 8 min - a total of $110 \mathrm{~min}$ of runtime, including a $10 \mathrm{~min}$ post-run reconditioning step. Centroided MS scan spectra were acquired in positive mode in the range of 300 to 1700 Da with a $6 \mathrm{~Hz}$ sampling; top 5 ions, preferring +2 and +3 species, were selected for MS/MS analysis, setting an active exclusion of the same precursor after 2 spectra over 0.15 minutes. Tandem mass spectra were recorded in the mass range 50 to $1700 \mathrm{Da}$ with a sampling rate of $3 \mathrm{~Hz}$. Collision energy was ramped with a slope of 3.6 and an offset of -3 V. Automatic QToF calibration was performed before each run. Each sample was run twice; analytical controls (a mix of baker's yeast enolase and bovine serum albumin tryptic digests) were run daily to monitor chromatographic performances.

MassHunter produced mzData.xml raw data that were searched against Swiss Prot database (SwissProt_57.15.fasta) using an in-house MASCOT Server (version 2.4, Matrix Science, UK) with the following settings: $30 \mathrm{ppm}$ parent ion tolerance, $0.15 \mathrm{Da}$ fragment ion tolerance, semi tryptic cleavage with two allowed missed cuts, pyridylethyl-cysteine and oxidized methionine as fixed. A concomitant search was performed with a database accounting for common non-human contaminants. MASCOT results were processed with Mascot Percolator, a semi-supervised machine learning algorithm for rescoring database search results (http:// www.sanger.ac.uk/resources/software/mascotpercolator). A MASCOT ion score $\geq 50$ for peptide identifications was required. Peptides reported by search engine were accepted only if they met the false discovery rate of $p<0.05$.

\section{Label-free relative quantification}

Exported re-scored MASCOT search results were cross-related to the corresponding MS1 profiles (mzXML format), converted from the vendor's raw data by trapper, http://sourceforge.net/projects/sashimi/files/trapper (Mass Hunter converter) by the quantitative software Ideal-Q [22], v. 1.024. Pooled search iMGN unique hits were manually validated and quantified on the moverz/RT 2D map. Peptide raw XIC data were exported and elaborated through the DanteR tool (https://omics.pnl.gov/software/danter) [23]. Briefly, peak areas were $\log _{2}$ transformed, normalized (central tendency), then corresponding protein intensities were obtained from the peptides through an analysis of variance $\left(p\right.$-value $<0.05, \log _{2} 0.5<$ protein ratio $>\log _{2} 2$ ) and the inferred values were evaluated for statistical significance of differentially expressed proteins throughout the groups under study.

False discovery rate was estimated through a concatenated decoy database search and was lower than $1 \%$ in all the search results. Percolated hits were visualized by protein family grouping and exported as XML or CSV with MudPIT scoring, reporting only unique peptide hits and the highest ranked proteins of each family.

\section{Cell invasion assay}

Cell invasion was assessed by Boyden blindwell chambers containing poly-vinyl-pyrrolidone-free polycarbonate filters, $8-\mu \mathrm{m}$ pore size coated with Matrigel (Sigma, Saint Louis, MO, USA). Twenty-four hours after the transfection, $5.0 \times 10^{4}$ HepG2, $3.0 \times 10^{4}$ SNU449 and $3.5 \times 10^{4}$ SNU398 cells were resuspended in serumfree medium and added to the upper chamber. A medium supplemented with $30 \%$ FBS was used as chemoattractant to the lower chamber. After $24 \mathrm{~h}$ and $48 \mathrm{~h}$ of incubations, non-invading cells were removed from the upper surface of the filter with cotton swabs. Invasive cells were fixed with 4\% paraformaldehyde, stained with Giemsa (Sigma), and counted under a microscope.

\section{Wound healing assay}

SNU398 and SNU449 cells were grown to confluence in regular medium, and then were maintained in serum-free medium for $48 \mathrm{~h}$. The monolayers were scratched using a P200 pipette tip, rinsed and photographed (t0), ( $\mathrm{t} 1),(\mathrm{t} 2)$. Images are representatives of three different experiments. Scratched monolayers were fixed in cold methanol and incubated with Ki67 antibody (Dako) for the evaluation of cell proliferation in the wound area. Negative controls were obtained by omitting the primary antibody.

\section{Gelatin zymography}

Gelatinolytic activity and quantity in conditioned media were analyzed by gelatin zymography as previously described [44]. 


\section{RNA analysis}

Total cellular RNA was prepared using Trizol (InVitrogen, Paisley, Scotland) according to the manufacturer's instructions. One microgram of total RNA was reverse-transcribed using Superscript II (InVitrogen). Relative gene expressions were determined by semiquantitative end-point PCR. PCR primers were reported in Supplementary Table 1.

\section{Transfections}

HepG2 cells were seeded into 6 well plates and grown to $\sim 40 \%$ confluence prior to Lipofectamine 2000 (InVitrogen) transfection with $40 \mathrm{nM}$ of human E-Cadherin specific siRNAs or scrambled siRNAs (InVitrogen). Cells were harvested $24 \mathrm{~h}$ and $48 \mathrm{~h}$ after transfection and pellet was used for protein and extractions.

For plasmid transfection SNU398 cells were seeded into 6 well plates and transfected with $0,2 \mu \mathrm{g}$ of pCMV6XL4-CDH1 plasmid, containing the full length human CDH1 cDNA, or empty vector pCMV6-XL4 (OriGene Technologies, Rockville, MD) using Lipofectamine 2000. Analyses of proteins expression were performed $24 \mathrm{~h}$ post transfection.

\section{Immunocytochemistry}

Cells were seeded on sterilized coverslips and fixed in $4 \%$ paraformaldeyde. Cells were then permeabilized in PBS containing $0.1 \%$ of saponin and incubated with normal goat serum at RT for $30 \mathrm{~min}$. E-Cadherin and Notch1 proteins localization was assessed by using the same antibodies used in Western blot (Dako) followed by a HRP-rabbit EnVision system with diaminobenzidine (DAB) (Sigma) as chromogen. Cells were then counterstained with Mayer's hematoxylin and mounted with DPX (BDH Chemical, Poole, UK). Negative controls were obtained by omitting the primary antibody.

\section{Patients}

HCC tissues from 38 patients (33 males and 5 females; median age: $70 \mathrm{y}$, range: $51-82$ y) who underwent liver resection for $\mathrm{HCC}$ at the Department of Surgery of the University of Bologna, entered in the study. Tissue samples were collected during surgery and stored as previously described [45]. Informed consent was obtained from each patient. Histopathologic grading was scored according to Edmondson and Steiner's criteria (Edmondson HA, cancer). Exclusion criteria were a previous history of local or systemic treatments for HCC. In addition, to avoid cases in which aberrant methylation of E-Cadherin could represent a confusing factor to examine the relationship between Notch1 and E-Cadherin protein expression, HCC cases with low levels of
E-CADHERIN mRNA were excluded from the analysis. Eighteen paraffin-embedded HCCs were obtained from the Addarii Institute of Oncology and Transplantation Pathology, S.Orsola-Malpighi Hospital and were used to assay Notch1 cellular localization.

\section{Immunohistochemistry}

Notch1 expression was immunohistochemically assessed on 18 formalin-fixed, paraffin-embedded sections. Endogenous peroxidase was inhibited by incubating slides in $3 \% \mathrm{H}_{2} \mathrm{O}_{2}$-methanol for $20 \mathrm{~min}$ at $4^{\circ} \mathrm{C}$. For antigen retrieval, slides were immersed in $\mathrm{pH} 6.0$ citrate buffer and boiled using a microwave oven. Negative controls were obtained by omitting the primary antibody. Immunoreactivity was revealed with the EnVision system (DAKO), and diaminobenzidine (DAB) as chromogen (Sigma). Slides were counterstained in Meyer's hematoxylin, coverslipped and examined by light microscopy. Staining of sections was assessed on 10 randomly selected fields at $40 \mathrm{X}$ by two independent observers (C.G, L.G.). Results represent the average of the percentage from ten $40 \mathrm{X}$ magnification fields.

\section{Serum analysis}

Twenty one serum samples from patients $(n=7$ cirrhosis, $n=7$ HCC early and $n=7$ HCC advanced) were obtained from Sant'Orsola-Malpighi Hospital. Written informed consent was obtained from all patients. Pools of healthy serum were also included in the study. None of these patients underwent surgery. Blood samples were left at RT for a minimum of 30 min (and maximum of $60 \mathrm{~min}$ ) to allow clot formation, and then, centrifuged at $3000 \mathrm{~g}$ for $10 \mathrm{~min}$ at $4^{\circ} \mathrm{C}$. The serum was aliquoted and stored at $-80^{\circ} \mathrm{C}$ until use. Albumin was depleted according to the manufacturer's instruction of Proteo-Extract Albumin removal kit (Calbiochem, Germany). Albumin depleted serum was precipitated overnight in acetone, centrifuged at $18800 \mathrm{rcf}$ for $20 \mathrm{~min}$ at $4^{\circ} \mathrm{C}$ and the pellets were dried in speed vacuum for 30 minutes at RT. Pellets were resospended in $8 \mathrm{M}$ urea and a mixture of phosphatase and protease inhibitors.

\section{Thbs1 detection in human serum}

Thbs1 was detected in the serum of 18 patients obtained from the Department of Surgery of the University of Bologna by using the human Thbs1 Elisa Kit (Biorbyt Ltd, Cambridge, United Kingdom) according to the manufacturer's instructions.

\section{Rats HCC induction}

One hundred and twenty male Wistar rats were obtained from Harlan Italy (Udine, Italy) and were housed 
in an animal facility at Sant'Orsola-Malpighi Hospital (Bologna, Italy). Animals were maintained at a temperature of $20-22^{\circ}$ and fed with a standard pellet diet ad libitum. The protocols of the experiments were approved by the Ethical Committee of the University of Bologna in accordance with European legislation. Hepatocellular carcinomas (HCCs) were induced by diethylnitrosamine (DENA) added in their drinking water for 8 weeks as previously described [46]. After this period, animals were monitored to check HCC's development by weekly ultrasound examination. One hundred and six rats developed liver nodules and were sacrificed as soon as the ultrasound showed the onset of HCC nodules. Tumor nodules and non-tumor liver tissue distant from the HCC nodules were collected and snapfrozen in liquid nitrogen or fixed in $10 \%$ formalin and paraffin embedded for histopathological analysis The remaining 14 rats were monitored for at least 2 months and no nodules were detected both at ultrasound examination and at sacrifice. Liver tissue was collected and snap-frozen in liquid nitrogen or fixed in $10 \%$ formalin and paraffin embedded for histopathological analysis. All 14 rats that did not develop HCC entered the study while among 106 rats that developed $\mathrm{HCC}$, we chose 18 rats with less than 2 liver nodules each, of nodules less than $5 \mathrm{~mm}$ and without histopathological identifiable micro-lesions in the nontumor liver distant from HCC.

\section{SDS-PAGE and Western blot analysis}

Protein extraction and immunoblotting were performed as previously described [47]. Primary antibodies were as follows: anti-Notch1 (Clone A6 Novus Biologicals, Cambridge, UK), anti-Thbs1(sc-73158, Santa Cruz Biotechnology, Santa Cruz, CA, USA), anti-E-Cadherin (Clone NCH-38, Dako, Denmark) anti-mTor (2993, Cell Signaling Technology, Beverly, MA), anti-Icam5 (Abcam, Cambridge, UK), anti Pai3 (sc-99153, Santa Cruz Biotechnology), anti-Vimentin (Clone V9, Dako), anti Ck19 (Clone RCK108, Dako), anti-Ck18 (Clone DC10, Dako), anti-Mmp-9 (Clone 6-6B, Calbiochem, San Diego, USA), anti-Snail (sc-28199, Santa Cruz Biotechnology), anti-Ck8 (sc-52324, Santa Cruz Biotechnology), antiAlpha-Sma (Clone 1A4, Sigma), anti-E-Cadherin (Clone $4 \mathrm{~A} 2$, Cell Signaling) and anti- $\beta$-Actin monoclonal antibody (Clone AC-40). Immunoreactivities were revealed with the EnVision dextran polymer visualization system (Dako). Membranes were washed and autoradiographies were obtained using a chemiluminescence reaction (ECL reagents, Amersham). Digital images of autoradiographies were acquired with a scanner (Fluor-S Multilmager, Bio$\mathrm{Rad}$ ) and signals were acquired in the linear range of the scanner and quantified using specific densitometric software (QUANTITY-ONE, Bio-Rad) in absorbance units.

\section{Statistical analysis}

After testing the distributions normality with the Shapiro-Wilk test, differences between groups were analysed using a double-sided Student $t$-test. Experimental data are expressed as the mean $\pm \mathrm{SE}$ from three independent experiments. $T$-test was also used to search significant difference in Notch1 and E-Cadherin expression in human cirrhosis and in non-tumor rat liver tissues. Pearson's correlation was used to explore the relationships between Notch1 and E-Cadherin expression in human HCC tissues. Pearson's correlation was also used to explore the relationships between Notch1 expression in human HCC evaluated by immunohistochemistry and Thbs 1 serum levels evaluated by ELISA. The Kaplan-Meyer survival analysis was used to compare patient's survival and time to recurrence (TTR) based on different Notch1 and E-Cadherin expression levels (the cut-off values were chosen on the basis of the median values) and statistical $p$ value was generated by the Cox-Mantel log-rank test. Survival analyses were performed considering only cancerrelated deaths whereas events related with other causes, including liver failure, were excluded.

$P$-values less than 0.05 were considered statistically significant. Statistical analyses were performed using SPSS version 19.0.

\section{ACKNOWLEDGMENTS AND FUNDING}

This work was supported by grants from Fondazione Cassa di Risparmio in Bologna (CARISBO) to L.B and Programma di Ricerca Regione- Università 2010-2012, Regione Emilia-Romagna, Bando "Ricerca Innovativa", to L.B. and L.G. The manuscript was proofread by Jenelyn Runatay from Pingu's English School of Bologna.

\section{CONFLICTS OF INTEREST}

No, there is no conflicts of interest.

\section{REFERENCES}

1. Ferlay J, Soerjomataram I, Dikshit R, Eser S, Mathers C, Rebelo M, Parkin DM, Forman D, Bray F. Cancer incidence and mortality worldwide: Sources, methods and major patterns in GLOBOCAN 2012. Int J Cancer. 2015; 136:E359-386.

2. Llovet JM, Ricci S, Mazzaferro V, Hilgard P, Gane E, Blanc JF, de Oliveira AC, Santoro A, Raoul JL, Forner A, Schwartz M, Porta C, Zeuzem S, et al. Sorafenib in advanced hepatocellular carcinoma. N Egl J Med. 2008; 359 : 378-390. 
3. Maida M, Iavarone M, Raineri M, Camma C, Cabibbo G. Second line systemic therapies for hepatocellular carcinoma: Reasons for the failure. World J Hepatol. 2015; 7: 2053-2057.

4. Artavanis-Tsakonas S, Rand MD, Lake RJ. Notch signaling: cell fate control and signal integration in development. Science. 1999; 284:770-776.

5. Purow B. Notch inhibition as a promising new approach to cancer therapy. Adv Exp Med Biol. 2012; 727:305-319.

6. Yuan X, Wu H, Xu H, Xiong H, Chu Q, Yu S, Wu GS, Wu K. Notch signaling: an emerging therapeutic target for cancer treatment. Cancer letters. 2015; 369:20-27.

7. Wang Z, Banerjee S, Li Y, Rahman KM, Zhang Y, Sarkar FH. Down-regulation of notch-1 inhibits invasion by inactivation of nuclear factor-kappaB, vascular endothelial growth factor, and matrix metalloproteinase- 9 in pancreatic cancer cells. Cancer Res. 2006; 66:2778-2784.

8. Adhami VM, Siddiqui IA, Sarfaraz S, Khwaja SI, Hafeez BB, Ahmad N, Mukhtar H. Effective prostate cancer chemopreventive intervention with green tea polyphenols in the TRAMP model depends on the stage of the disease. Clin Cancer Res. 2009; 1:1947-1953.

9. Asnaghi L, Ebrahimi KB, Schreck KC, Bar EE, Coonfield ML, Bell WR, Handa J, Merbs SL, Harbour JW, Eberhart CG. Notch signaling promotes growth and invasion in uveal melanoma. Clin Cancer Res. 2012; 18:654-665.

10. Lim SO, Kim HS, Quan X, Ahn SM, Kim H, Hsieh D, Seong JK, Jung G. Notch1 binds and induces degradation of Snail in hepatocellular carcinoma. BMC Biol. 2011; 9:83.

11. Wang XQ, Zhang W, Lui EL, Zhu Y, Lu P, Yu X, Sun J, Yang S, Poon RT, Fan ST. Notch1-Snail1-E-cadherin pathway in metastatic hepatocellular carcinoma. Int J Cancer. 2012; 131:E163-172.

12. Ranganathan $\mathrm{P}$, Weaver KL, Capobianco AJ. Notch signalling in solid tumours: a little bit of everything but not all the time. Nat Rev Cancer. 2011; 11:338-351.

13. Giovannini C, Gramantieri L, Chieco P, Minguzzi M, Lago F, Pianetti S, Ramazzotti E, Marcu KB, Bolondi L. Selective ablation of Notch3 in HCC enhances doxorubicin's death promoting effect by a p53 dependent mechanism. J Hepatol. 2009; 50:969-979.

14. Zhou L, Zhang N, Song W, You N, Li Q, Sun W, Zhang Y, Wang D,Dou K. The significance of Notch1 compared with Notch3 in high metastasis and poor overall survival in hepatocellular carcinoma. PloS one. 2013; 8:e57382.

15. Gounder MM, Schwartz GK. Moving forward one Notch at a time. J Clin Oncol. 2012; 30:2291-2293.

16. Huntzicker EG, Hotzel K, Choy L, Che L, Ross J, Pau G, Sharma N, Siebel CW, Chen X, French DM. Differential effects of targeting Notch receptors in a mouse model of liver cancer. Hepatology. 2015; 61:942-952.

17. Espinoza I, Miele L. Notch inhibitors for cancer treatment. Pharmacol Ther. 2013; 139:95-110.
18. Mungamuri SK, Yang X, Thor AD, Somasundaram K. Survival signaling by Notch1: mammalian target of rapamycin (mTOR)-dependent inhibition of p53. Cancer Res. 2006; 66:4715-4724.

19. Wilmanns C, Grossmann J, Steinhauer S, Manthey G, Weinhold B, Schmitt-Graff A, von Specht BU. Soluble serum E-cadherin as a marker of tumour progression in colorectal cancer patients. Clin Exp Metastasis. 2004; 21:75-78.

20. Carlson CB, Lawler J, Mosher DF. Structures of thrombospondins. Cell Mol Life Sci. 2008; 65:672-686.

21. Giovannini C, Gramantieri L, Minguzzi M, Fornari F, Chieco P, Grazi GL, Bolondi L. CDKN1C/P57 is regulated by the Notch target gene Hes1 and induces senescence in human hepatocellular carcinoma. Am J Pathol. 2012; 181:413-422.

22. Mitselou A, Batistatou A, Nakanishi Y, Hirohashi S, Vougiouklakis T, Charalabopoulos K. Comparison of the dysadherin and E-cadherin expression in primary lung cancer and metastatic sites. Histol Histopathol. 2010; 25:1257-1267.

23. Maeda K, Takemura M, Umemori M, Adachi-Yamada T. E-cadherin prolongs the moment for interaction between intestinal stem cell and its progenitor cell to ensure Notch signaling in adult Drosophila midgut. Genes Cells. 2008; 13:1219-1227.

24. Hoshida Y, Villanueva A, Llovet JM. Molecular profiling to predict hepatocellular carcinoma outcome. Exp Rev Gastroenterol Hepatol. 2009; 3:101-103.

25. El-Serag HB, Rudolph KL. Hepatocellular carcinoma: epidemiology and molecular carcinogenesis. Gastroenterology. 2007; 132:2557-2576.

26. Rajewsky MF, Dauber W, Frankenberg H. Liver carcinogenesis by diethylnitrosamine in the rat. Science. 1966; 152:83-85.

27. Gu Y, Masiero M, Banham AH. Notch signaling: its roles and therapeutic potential in hematological malignancies. Oncotarget. 2016. doi: 10.18632/oncotarget.7772.

28. Makawita S, Smith C, Batruch I, Zheng Y, Ruckert F, Grutzmann R, Pilarsky C, Gallinger S, Diamandis EP. Integrated proteomic profiling of cell line conditioned media and pancreatic juice for the identification of pancreatic cancer biomarkers. Mol Cell Proteomics. 2011; 10:M111 008599.

29. Chu PG, Weiss LM. Keratin expression in human tissues and neoplasms. Histopathology. 2002; 40:403-439.

30. Soyama A, Eguchi S, Takatsuki M, Kawashita Y, Hidaka M, Tokai H, Nagayoshi S, Mochizuki S, Matsumoto S, Hamasaki K, Tajima Y, Kanematsu T. Significance of the serum level of soluble E-cadherin in patients with HCC. Hepatogastroenterology. 2008; 55:1390-1393.

31. Zabrenetzky V, Harris CC, Steeg PS, Roberts DD. Expression of the extracellular matrix molecule thrombospondin inversely correlates with malignant progression in melanoma, lung and breast carcinoma cell lines. Int J. 1994; 59: 191-195. 
32. Sargiannidou I, Zhou J, Tuszynski GP. The role of thrombospondin-1 in tumor progression. Exp Biol Med. 2001; 226:726-733.

33. Kawahara N, Ono M, Taguchi K, Okamoto M, Shimada M, Takenaka K, Hayashi K, Mosher DF, Sugimachi K, Tsuneyoshi M, Kuwano M. Enhanced expression of thrombospondin-1 and hypovascularity in human cholangiocarcinoma. Hepatology. 1998; 28:1512-1517.

34. Iida H, Honda M, Kawai HF, Yamashita T, Shirota Y, Wang BC, Miao H, Kaneko S. Ephrin-A1 expression contributes to the malignant characteristics of \{alpha\}-fetoprotein producing hepatocellular carcinoma. Gut. 2005; 54:843-851.

35. Simmons MJ, Serra R, Hermance N, Kelliher MA. NOTCH1 inhibition in vivo results in mammary tumor regression and reduced mammary tumorsphere-forming activity in vitro. Breast Cancer Res. 2012; 14:R126.

36. Pascual S, Herrera I, Irurzun J. New advances in hepatocellular carcinoma. World J Hepatol. 2016; 8:421-438.

37. Poon RT, Fan ST, Ng IO, Wong J. Significance of resection margin in hepatectomy for hepatocellular carcinoma: A critical reappraisal. Ann Surg. 2000; 231:544-551.

38. Gall TM, Frampton AE. Gene of the month: E-cadherin (CDH1). J Clin Pathol. 2013; 66:928-932.

39. Wei Y, Van Nhieu JT, Prigent S, Srivatanakul P, Tiollais P, Buendia MA. Altered expression of E-cadherin in hepatocellular carcinoma: correlations with genetic alterations, beta-catenin expression, and clinical features. Hepatology. 2002; 36:692-701.

40. Osada T, Sakamoto M, Ino Y, Iwamatsu A, Matsuno Y, Muto T, Hirohashi S. E-cadherin is involved in the intrahepatic metastasis of hepatocellular carcinoma. Hepatology. 1996; 24:1460-1467.
41. Tryndyak VP, Ross SA, Beland FA, Pogribny IP. Downregulation of the microRNAs miR-34a, miR-127, and miR$200 \mathrm{~b}$ in rat liver during hepatocarcinogenesis induced by a methyl-deficient diet. Mol Carcinog. 2009; 48:479-487.

42. Villanueva A, Alsinet C, Yanger K, Hoshida Y, Zong Y, Toffanin S, Rodriguez-Carunchio L, Sole M, Thung S, Stanger BZ, Llovet JM. Notch signaling is activated in human hepatocellular carcinoma and induces tumor formation in mice. Gastroenterology. 2012; 143:1660-1669 e1667.

43. Geisler F, Strazzabosco M. Emerging roles of Notch signaling in liver disease. Hepatology. 2015; 61:382-392.

44. Fornari F, Gramantieri L, Giovannini C, Veronese A, Ferracin M, Sabbioni S, Calin GA, Grazi GL, Croce CM, Tavolari S, Chieco P, Negrini M, Bolondi L. MiR-122/ cyclin G1 interaction modulates p53 activity and affects doxorubicin sensitivity of human hepatocarcinoma cells. Cancer Res. 2009; 69:5761-5767.

45. Gramantieri L, Giovannini C, Lanzi A, Chieco P, Ravaioli M, Venturi A, Grazi GL, Bolondi L. Aberrant Notch3 and Notch4 expression in human hepatocellular carcinoma. Liver int. 2007; 27:997-1007.

46. Giovannini $C$, Minguzzi M, Baglioni M, Fornari F, Giannone F, Ravaioli M, Cescon M, Chieco P, Bolondi L, Gramantieri L. Suppression of p53 by Notch3 is mediated by Cyclin G1 and sustained by MDM2 and miR-221 axis in hepatocellular carcinoma. Oncotarget. 2014; 5:10607-10620. doi: 10.18632/oncotarget.2523.

47. Giovannini C, Lacchini M, Gramantieri L, Chieco P, Bolondi L. Notch3 intracellular domain accumulates in HepG2 cell line. Anticancer Res. 2006; 26:2123-2127. 